Prepared for the U.S. Department of Energy under Contract DE-AC05-76RL01830

\title{
Methods for Attribute Measurement and Alternatives to Multiplicity Counting
}

RT Kouzes

BD Geelhood

May 2000

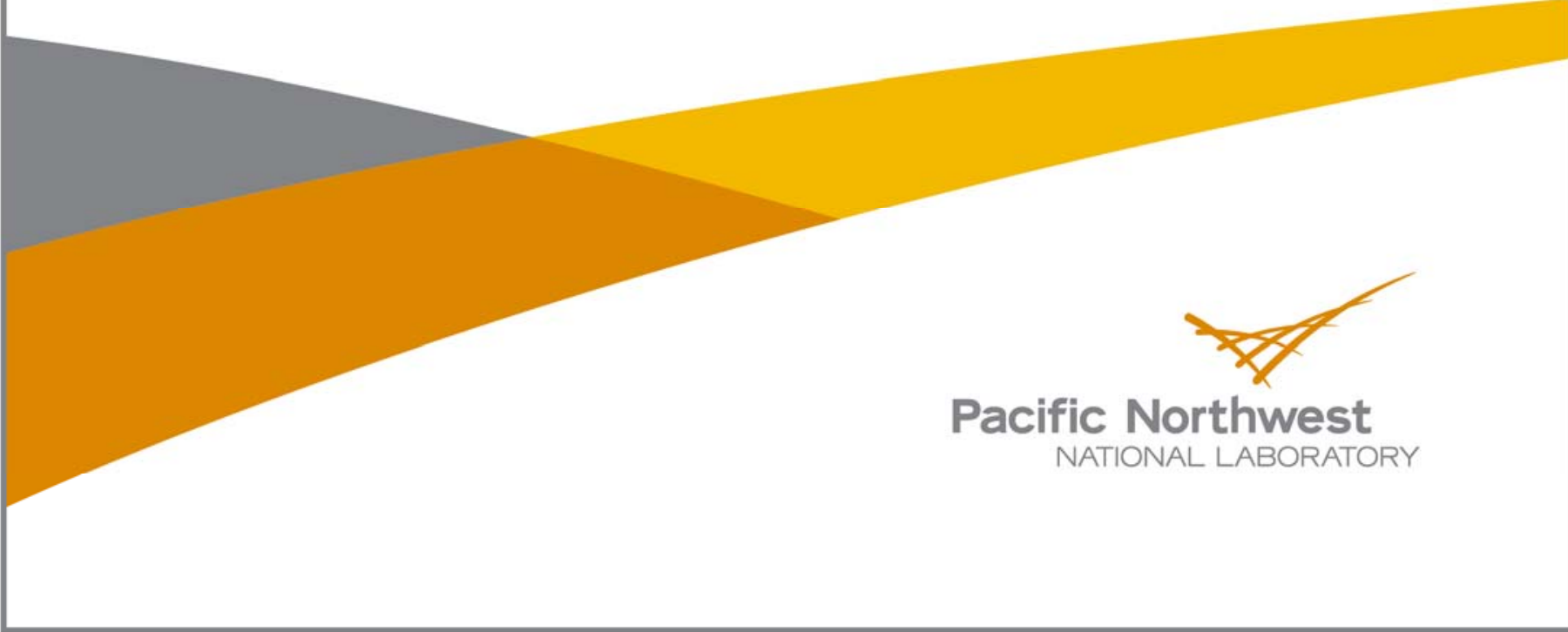




\title{
DISCLAIMER
}

This report was prepared as an account of work sponsored by an agency of the United States Government. Neither the United States Government nor any agency thereof, nor Battelle Memorial Institute, nor any of their employees, makes any warranty, express or implied, or assumes any legal liability or responsibility for the accuracy, completeness, or usefulness of any information, apparatus, product, or process disclosed, or represents that its use would not infringe privately owned rights. Reference herein to any specific commercial product, process, or service by trade name, trademark, manufacturer, or otherwise does not necessarily constitute or imply its endorsement, recommendation, or favoring by the United States Government or any agency thereof, or Battelle Memorial Institute. The views and opinions of authors expressed herein do not necessarily state or reflect those of the United States Government or any agency thereof.

\author{
PACIFIC NORTHWEST NATIONAL LABORATORY \\ operated by \\ BATTELLE \\ for the \\ UNITED STATES DEPARTMENT OF ENERGY \\ under Contract DE-AC05-76RL01830
}

Printed in the United States of America

Available to DOE and DOE contractors from the

Office of Scientific and Technical Information,

P.O. Box 62, Oak Ridge, TN 37831-0062;

ph: (865) 576-8401

fax: $(865) 576-5728$

email: reports@adonis.osti.gov

\footnotetext{
Available to the public from the National Technical Information Service, U.S. Department of Commerce, 5285 Port Royal Rd., Springfield, VA 22161 ph: (800) 553-6847 fax: $(703) 605-6900$

email: orders@ntis.fedworld.gov

online ordering: http://www.ntis.gov/ordering.htm
}

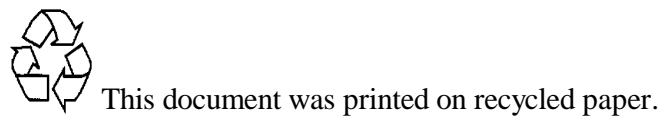




\section{Methods for Attribute Measurement and Alternatives to Multiplicity Counting}

RT Kouzes

BD Geelhood

May 2000

Prepared for

the U.S. Department of Energy

under Contract DE-AC06-76RLO 1830

Pacific Northwest National Laboratory

Richland, Washington 99352 


\section{Summary}

Attribute measurement systems are being developed in support of arms-reduction negotiations to verify compliance with the disassembly of nuclear weapons. The current demonstration attribute measurement system consists of a high-resolution gamma detector plus a neutron multiplicity counter. This document examines alternative configurations from this demonstration system for attribute measurement. 


\section{Acronyms}

$\begin{array}{ll}\text { AMS/IB } & \text { Attribute Measurement System with Information Barrier } \\ \text { CTR } & \text { Cooperative Threat Reduction } \\ \text { DTRA } & \text { Defense Threat Reduction Agency } \\ \text { FMTT-AMS } & \text { Fissile Material Transparency Talks-Attribute Measurement System } \\ \text { HPGe } & \text { high-purity germanium } \\ \text { MME } & \text { Minimum Mass Estimate } \\ \text { NMC } & \text { neutron multiplicity counter } \\ \text { NMIS } & \text { Nuclear Materials Inspection System } \\ \text { TRADS } & \text { Trusted Radiation Attribute Demonstration System }\end{array}$




\section{Contents}

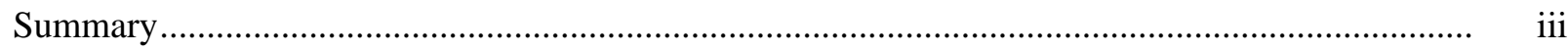

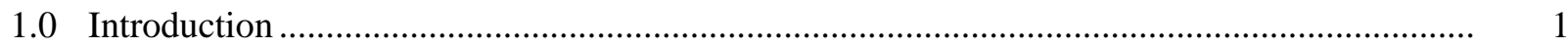

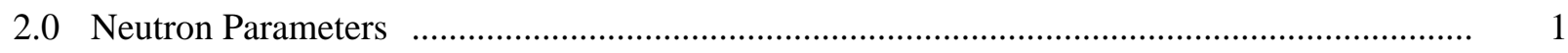

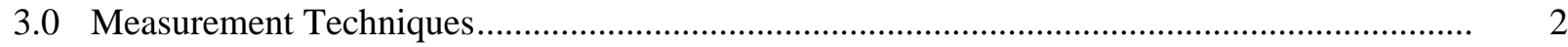

3.1 Neutron Measurement Techniques .................................................................... 2

3.2 Gamma Measurement Techniques........................................................................ 4

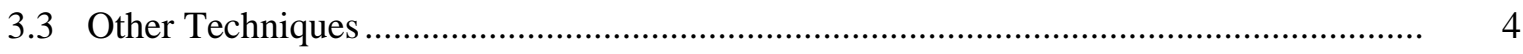

4.0 Attribute Determination .........................................................................................

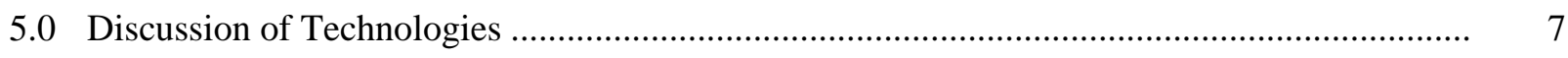

5.1 HPGe Plus Singles Neutron Measurement with Energy Determination ......................... 7

5.2 HPGe Plus Doubles Neutron Measurement.................................................................. 8

5.3 HPGe Plus Multiplicity Neutron Measurement ......................................................... 8

5.4 HPGe Plus Fast Neutron/Gamma Measurement.........................................................

6.0 Optimal System Configurations …..........................................................................

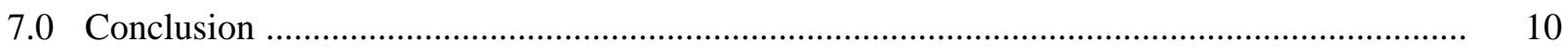

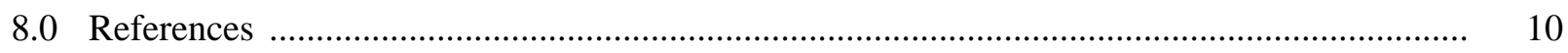




\section{Tables}

3.1 Existing Technologies that Can Be Applied to Mass Attribute Measurement ........................ 3

4.1 Summary of Technology Utilization for Attribute Determination........................................... 6

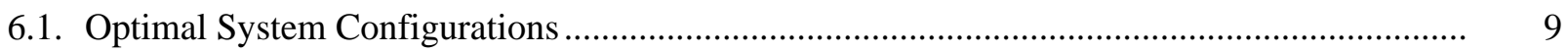

viii 


\subsection{Introduction}

The Attribute Measurement System with Information Barrier (AMS/IB) specification is being developed in support of the Defense Threat Reduction Agency's (DTRA's) Cooperative Threat Reduction (CTR) program for the Mayak Fissile Material Storage Facility. This document discusses the technologies available for attribute measurement, and advantages and disadvantages of alternatives.

Neutron and gamma ray counting technologies can be combined to measure various aspects of the defined six attributes of plutonium from a fission weapon

- presence of plutonium $\left({ }^{239} \mathrm{Pu}\right.$ to $99.9 \%$ confidence or greater)

- isotopic composition of the plutonium is less than $10 \%{ }^{240} \mathrm{Pu}\left({ }^{240} \mathrm{Pu} /{ }^{239} \mathrm{Pu}\right.$ to $\left.5 \%\right)$

- mass of the plutonium (to $10 \%$ of true mass $90 \%$ of the time)

- plutonium age (separated before January 1997)

- plutonium in metal form rather than oxide form

- axial symmetry.

The draft statement of work gives the functional requirements given in parentheses above. These values have a consequence on the determination of the system to be used in the measurement.

\subsection{Neutron Parameters}

Neutrons arise from spontaneous and induced fission, and from $(\alpha, n)$ reactions on light elements in or around the alpha emitting element. Each fission on average produces multiple neutrons per event. A single ${ }^{240} \mathrm{Pu}$ spontaneous fission produces 0 to 6 neutrons, with $<v\left({ }^{240} \mathrm{Pu}\right)>=2.16$ (PANDA p. 342). The energy distributions of fission neutrons and $(\alpha, n)$ neutrons are very different, which implies that a neutron energy measurement can help separate these two sources of neutrons.

Neutrons can induce fission events in fissile material, which gives rise to a third neutron parameter, the multiplication factor. Weapons components are designed with low $\mathrm{k}_{\text {eff }}$ to facilitate storage, which implies that the multiplication factor is small for weapons origin material. Ignoring multiplication in a measurement increases the mass estimate. The effect of multiplication increases with increasing sample mass (PANDA 1991) and the average distance through the fissile material that emitted neutrons travel. For a near 500-gram mass (the unclassified threshold mass established for weapon's origin material), the 
total neutron count rate increases by about $5 \%$ due to multiplication which would increase the coincidence response by about $28 \%$ if the electronics are not adjusted to reject multiple pairs from coincident bursts. Thus, at the threshold mass of 500-grams, the maximum overestimate of the mass would be $28 \%$, and would likely be much less in practice. Electronically gating out signals during a time window following a coincidence would significantly reduce or eliminate the multiplication factor. Empirical adjustment of the mass threshold could correct for ignoring multiplication.

Singles measurements only determine the total flux of neutrons, which is a combination of $(\alpha, n)$ reaction neutrons and fission neutrons. If it is known that the source composition is metallic, the $(\alpha, n)$ component can be negligible and singles can provide an adequate measure of the plutonium mass. Alternately, information on the neutron energy spectrum can provide a means to separate the fission neutron flux from the $(\alpha, n)$ flux.

Doubles measurements find the singles rate and the coincidence rate, which allows a determination of the fission rate (and thus plutonium mass) and the $(\alpha, n)$ flux. The efficiency of the neutron counters must be greater than about $1 \%$ for the determination of the doubles rate. Multiplication is either estimated or ignored for doubles measurements. Alternately, if the $(\alpha, n)$ contribution is negligible, both the mass and multiplication can be determined.

Triples measurements find the singles neutron flux, the double coincidence rate, and the triple coincidence rate, which allows a measure of the fission rate (and thus plutonium mass),the $(\alpha, n)$ flux, and the multiplication. Multiplicity counters can detect even higher orders of coincident neutrons. Multiplication in the source can produce large numbers of additional neutrons through induced chain-reactions. Thus, up to 20 coincident neutrons can be observed from ${ }^{240} \mathrm{Pu}$ with a neutron detection efficiency of $56 \%$ (Romeo 1998) in a neutron multiplicity counter.

\subsection{Measurement Techniques}

Table 3.1 provides a summary of existing technologies for attribute determination through nondestructive, non-invasive testing. All of these techniques can be hidden behind an information barrier. Briefly these methods are

\subsection{Neutron Measurement Techniques}

- Neutron multiplicity measurements utilize an array of moderated pressurized helium-3 detectors to determine singles, doubles, triples (or more) coincidences. Fission produces multiple neutrons, with a range of about 0-6 per fission, plus the multiplication that occurs through induced fission in the material. It is this multiplicity of total neutrons produced by a fission event which is measured by a multiplicity detector. With sufficient data, these instruments provide a measure of three neutron parameters, typically the material mass, $(\alpha, n)$ contribution, and neutron multiplication factor. These 
Table 3.1. Existing Technologies that Can Be Applied to Mass Attribute Measurement

\begin{tabular}{|c|c|c|c|}
\hline Method & Pros & Cons & "Most Appropriate \\
\hline \multicolumn{4}{|l|}{ Neutron Counting } \\
\hline $\begin{array}{l}\text { Singles Neutron } \\
\text { Counting }\end{array}$ & $\begin{array}{l}\text { - } \text { Light weight portable } \\
\text { - } \text { Easy to use } \\
\text { - } \text { Used by RANGER \& } \\
\text { TRADS }\end{array}$ & $\begin{array}{ll}\text { - } & \text { Requires isotopics } \\
\text { - } & \text { One neutron parameter } \\
& \text { measured (mass) }\end{array}$ & $\begin{array}{l}\text { Best choice when sample } \\
\text { type is known or mini- } \\
\text { mum information is } \\
\text { required }\end{array}$ \\
\hline $\begin{array}{l}\text { Portable or Non- } \\
\text { Portable Coincidence } \\
\text { Neutron Counting } \\
\text { (Singles and Doubles) }\end{array}$ & $\begin{array}{l}\text { - Less expensive than NMC } \\
\text { - Simpler to use } \\
\text { - Lower efficiency neutron } \\
\text { detection is required }\end{array}$ & $\begin{array}{ll} & \text { Requires isotopics } \\
\text { - } & \text { Two neutron parameters } \\
& \text { measured [mass, (a,n)] }\end{array}$ & $\begin{array}{l}\text { Best choice when some } \\
\text { attributes are known (e.g. } \\
\text { known composition) }\end{array}$ \\
\hline $\begin{array}{l}\text { Multiplicity Neutron } \\
\text { Counting (LANL) } \\
\text { (Triples or More) }\end{array}$ & $\begin{array}{l}\text { - } \text { Works with less } \\
\text { information } \\
\text { - } 3 \text { neutron parameters } \\
\text { measured [mass, }(\alpha, \mathrm{n}), \& \\
\text { multiplication] } \\
\text { - } \text { Better accuracy }\end{array}$ & $\begin{array}{l}\text { - } \text { Big and heavy } \\
\text { - Expensive } \\
\text { - Complex } \\
\text { - Less flexible } \\
\text { - Requires isotopics }\end{array}$ & $\begin{array}{l}\text { - Best when fewer other } \\
\text { attributes are known }\end{array}$ \\
\hline $\begin{array}{l}\text { Active Neutron Induced } \\
\text { Coincidence (Using } \\
\text { above Neutron } \\
\text { Detection Hardware) }\end{array}$ & $\begin{array}{ll}\text { - } & \text { Provides additional } \\
\text { attribute information from } \\
\text { neutron source induced } \\
\text { multiplication }\end{array}$ & $\begin{array}{l}\text { - } \text { Requires neutron source } \\
\text { - } \text { Much more complex }\end{array}$ & $\begin{array}{l}\text { Best choice as an added } \\
\text { measurement with singles } \\
\text { or doubles measurement if } \\
\text { complexity not an issue }\end{array}$ \\
\hline $\begin{array}{l}\text { Neutron Energy } \\
\text { Spectroscopy }\end{array}$ & $\begin{array}{l}\text { Provides additional } \\
\text { information for neutron } \\
\text { counters to determine ( } \alpha \text {, } \\
\text { n) contribution } \\
\end{array}$ & $\begin{array}{l}\text { - Potentially added } \\
\text { complexity }\end{array}$ & $\begin{array}{l}\text { - Can be implemented with } \\
\text { inexpensive detectors in } \\
\text { neutron counting systems }\end{array}$ \\
\hline \multicolumn{4}{|l|}{ Gamma Spectroscopy } \\
\hline $\begin{array}{l}\text { HPGe Spectroscopy, } \\
\text { E.G. Minimum Mass } \\
\text { Estimate (MME) Using } \\
\text { Gamma Spectra (SNL) }\end{array}$ & $\begin{array}{ll}\text { - } & \text { Only HPGe required } \\
\text { - } & \text { Provides minimum mass } \\
& \text { value } \\
\text { - } & \text { Luggable detection and } \\
& \text { analysis system } \\
\text { - } & \text { Used by TRADS } \\
\end{array}$ & $\begin{array}{ll}- & \text { Only provides } \\
\text { minimum mass value } \\
\text { - } \\
\text { Requires sophisticated } \\
\text { analysis of high-res } \\
\text { gamma spectra }\end{array}$ & $\begin{array}{l}\text { Best choice when only } \\
\text { minimum mass or mass } \\
\text { threshold information is } \\
\text { needed } \\
\text { - Best if neutron sensor not } \\
\text { desired }\end{array}$ \\
\hline \multicolumn{4}{|l|}{ Other Methods } \\
\hline $\begin{array}{l}\text { Templating with } \\
\text { Neutrons or Gamma } \\
\text { Rays }\end{array}$ & $\begin{array}{ll}\text { - } & \text { Multiple detector } \\
\text { technologies could be } \\
\text { utilized Highly accurate } \\
\text { - } & \text { Simple to use }\end{array}$ & $\begin{array}{l}\text { - } \text { Requires initialization } \\
\text { to build a basis for } \\
\text { comparison } \\
\text { - } \text { Potential for classified } \\
\text { templates }\end{array}$ & $\begin{array}{l}\text { - Best choice for "partially" } \\
\text { classified items to confirm } \\
\text { stated sample } \\
\text { characteristics }\end{array}$ \\
\hline Calorimetry & $\begin{array}{l}\text { - Simple measurement of } \\
\text { heat production to infer } \\
\text { mass } \\
\text { - Well developed technique }\end{array}$ & $\begin{array}{l}\text { - Requires isotopics } \\
\text { - Slow }\end{array}$ & $\begin{array}{l}\text { - Possible choice for known } \\
\text { sample composition }\end{array}$ \\
\hline $\begin{array}{l}\text { Nuclear Materials } \\
\text { Inspection System } \\
\text { (Nmis) (Ornl) }\end{array}$ & $\begin{array}{l}\text { - } \text { Uses time tagged } \\
\text { neutron/gamma source to } \\
\text { interrogate sample } \\
\text { - } \text { Gives mass } \\
\text { - } \quad \text { Small and cheap sensors } \\
\end{array}$ & $\begin{array}{l}\text { - } \text { Requires other attribute } \\
\text { information } \\
\text { - Complex } \\
\text { implementation }\end{array}$ & $\begin{array}{l}\text { - } \text { Best choice for some } \\
\text { sample types } \\
\text { - } \text { Best choice for in situ } \\
\text { measurements }\end{array}$ \\
\hline $\begin{array}{l}\text { Gamma Measurement } \\
\text { from Neutron Induced } \\
\text { Activity }\end{array}$ & $\begin{array}{l}\text { - Uses weak neutron source } \\
\text { to induce fission in sample }\end{array}$ & $\begin{array}{l}\text { - Requires other attribute } \\
\text { information }\end{array}$ & $\begin{array}{l}\text { - } \text { Best choice for some } \\
\text { sample types }\end{array}$ \\
\hline
\end{tabular}


instruments tend to be expensive, large, and utilize complex analysis. The plutonium isotopics are required to extract the plutonium mass from the spontaneous fission rate (Romero 1998).

- Portable or non-portable coincidence neutron measurements are similar to multiplicity measurements, but only determine singles and doubles rates. These instruments provide a measure of two neutron parameters, typically the material mass, and $(\alpha, n)$ contribution. Additional information is needed to determine the neutron multiplication factor (Peurrung et al. 1991).

- Singles neutron measurements use the same type of neutron detectors, but do not measure coincidences. They are typically inexpensive, hand-held devices that provide information on only one neutron parameter (Peurrung et al. 1991).

- Neutron energy spectrometry can be performed in a crude way by designing the above instruments to involve layers of neutron detectors with absorbers. For example, inexpensive Bonner spheres can be used to make singles measurements while determining a rough measure of the neutron energy. This information can be used to identify the neutron spectrum, which is a sum of the fission and (alpha, $\mathrm{n}$ ) contributions, and thus assist in the plutonium mass determination from the neutron singles measurement. Activation foils or time of flight are other methods for determining the total neutron spectrum (Knoll Date?).

- Active neutron induced measurements utilize any of the above instruments in conjunction with a neutron source which induces neutron multiplication (fission) in the sample and allows measurement of the multiplication factor (Peurrung et al. 1991).

\subsection{Gamma Measurement Techniques}

- Gamma counting with high-purity germanium (HPGe) detectors provides a measure of the plutonium mass, isotopic composition, age, and metal versus compound form.

- The Minimum Mass Estimate (MME) technique is a process that utilizes sophisticated analysis of gamma ray spectra to infer a minimum plutonium mass from the energy dependent attenuation of the gamma rays. The performance of the MME could be improved using empirical calibrations (as is done in the neutron multiplicity counter [NMC]), or using low energy gamma rays to provide more information about the attenuation factors of the source. ${ }^{(a)}$

\subsection{Other Techniques}

- Nuclear Materials Inspection System (NMIS) uses a time tagged neutron/gamma source and coincidence timing of plastic scintillator detected neutrons and gamma rays to determine sample characteristics. It can also be used passively without the neutron source to look for coincidences. It

(a) Mitchell, D. and P. Vanier. Minimum Mass Estimates for Plutonium Based on Peak Intensities and Scattered Radiation in HPGe Spectra. Private communication. 
is sensitive to both fission neutrons and the much more prolific fission gamma rays, which can produce a dead-time limitation. A measurement of gamma-neutron coincidence timing with NMIS can provide an estimate of the neutron energy spectrum by time-of-flight. This provides a measure of the $(\alpha, n)$ contribution to the neutron flux (Breeding et al. 1997).

- Gamma measurements from neutron induced activity utilizes a neutron source to induce activity in either a uranium or plutonium sample, followed by a measure of the gamma rays produced from the fission induced radionuclides (Beddingfield and Cecil 1998).

- Prompt neutron capture gamma ray measurements with a HPGe detector from a foil sample can directly measure the neutron flux without a separate neutron detector. Using a set of foil samples, the neutron energy spectrum can be determined. This would provide a measure of the $(\alpha, n)$ contribution to the neutron flux.

- Templating is a method of using either neutron or gamma spectra from known samples to be compared with an unknown. Through analysis, an unknown can be identified as the same as a specified known sample. ${ }^{\text {(a) }}$

- Calorimetry is the process of measuring heat production of a sample, and is a long used technology. Calorimetry requires the plutonium isotopic information to determine the plutonium mass (Peurrung et al. 1991).

\subsection{Attribute Determination}

Determination of the six attributes requires techniques involving either a high-resolution gamma ray measurement, or both neutron and gamma ray measurements. The high-resolution gamma ray measurement made by the HPGe detector is required to obtain the plutonium isotopic composition attribute, which cannot be determined from the neutron measurements. The neutron systems are most useful in determining the plutonium mass, but this information can also be provided by the HPGe system alone, as demonstrated by the MME analysis in the Trusted Radiation Attribute Demonstration System (TRADS). The HPGe is required to determine the age attribute, while symmetry can be determined by either neutron or gamma technology. The presence of metal versus plutonium compounds ("oxide”) can be determined to some degree by either gamma ray spectrometry or neutron energy spectrometry. The capability to measure multiple attributes has already been demonstrated using a HPGe detector with a multiplicity detector in the Fissile Material Transparency Talks - Attribute Measurement System (FMTT-AMS) demonstration in 60 minutes measurement time. The TRADS system has shown the ability to measure plutonium mass and the isotopic ratio with only a HPGe detector in 10 minutes measurement time. The

(a) Mitchell, D. and P. Vanier. Minimum Mass Estimates for Plutonium Based on Peak Intensities and Scattered Radiation in HPGe Spectra. Private communication. 
measurement of the "oxide" attribute is an open issue because of recent measurement results showing the $871 \mathrm{keV}$ peak is an indication of nitrogen rather than oxygen.

The key question is what is the optimal choice of technologies that provides a reasonable trade off of

- cost

- time of measurement

- flexibility of measurement

- protection of classified information

- confidence in the result (transparency and authentication), including spoofing.

Table 4.1 shows how each of a set of alternate detector technologies, either singly or in pairs, could be used to measure the six attributes. A "yes" as a table entry means that that technology can determine that attribute, whereas a blank means it cannot. For combined gamma and neutron detector systems, HPGe is shown if it is the source of the measurement, and added information from the neutron detector is indicated. The entry for HPGe plus fast $\mathrm{n}$ /gamma is a system based on plastic scintillator measurements as in the NMIS system. The plastic scintillator is sensitive to both neutrons and gamma rays, which can provide a measure of multiplicity (and thus plutonium mass).

Table 4.1. Summary of Technology Utilization for Attribute Determination

\begin{tabular}{|c|c|c|c|c|c|c|}
\hline Attribute & $\begin{array}{c}\text { Plutonium } \\
\text { Presence }\end{array}$ & $\begin{array}{c}\text { Plutonium } \\
\text { Mass }\end{array}$ & $\begin{array}{c}\text { Pu Isotopic } \\
\text { Composition }\end{array}$ & $\begin{array}{c}\text { Plutonium } \\
\text { Age }\end{array}$ & $\begin{array}{c}\text { Metal versus } \\
\text { Compound }\end{array}$ & $\begin{array}{c}\text { Axial } \\
\text { Symmetry }\end{array}$ \\
\hline Neutron Only & & & & & & Yes \\
\hline NaI Only & Yes & & & & & Yes \\
\hline HPGe+ Singles & HPGe & $\begin{array}{l}\text { Yes. }(\alpha, n) \text { via } \\
\text { HPGe, ignore } \\
\text { multiplication. }\end{array}$ & HPGe & HPGe & HPGe & $\begin{array}{l}\text { HPGe or } \\
\text { neutron }\end{array}$ \\
\hline HPGe Only (MME) & HPGe & Yes. (MME) & HPGe & HPGe & HPGe & HPGe \\
\hline $\begin{array}{l}\text { HPGe + Fast } \\
\text { N-Gamma TOF }\end{array}$ & HPGe & $\begin{array}{l}\text { Yes. }(\alpha, n) \text { via } \\
\text { HPGe + neutron } \\
\text { energy. }\end{array}$ & HPGe & HPGe & $\begin{array}{l}\text { HPGe + neutron } \\
\text { energy }\end{array}$ & $\begin{array}{l}\text { HPGe or } \\
\text { neutron }\end{array}$ \\
\hline $\begin{array}{l}\text { HPGe + Singles } \\
\text { Neutron + Neutron } \\
\text { Energy }\end{array}$ & HPGe & $\begin{array}{l}\text { Yes. }(\alpha, n) \text { via } \\
\text { HPGe + neutron } \\
\text { energy ignore } \\
\text { multiplication. }\end{array}$ & HPGe & HPGe & $\begin{array}{l}\text { HPGe + neutron } \\
\text { energy }\end{array}$ & $\begin{array}{l}\text { HPGe or } \\
\text { neutron }\end{array}$ \\
\hline $\begin{array}{l}\text { HPGe+ Doubles } \\
\text { Neutron }\end{array}$ & HPGe & $\begin{array}{l}\text { Yes. Ignore } \\
\text { multiplication. }\end{array}$ & HPGe & HPGe & $\mathrm{HPGe}+(\alpha, n)$ & $\begin{array}{l}\text { HPGe or } \\
\text { neutron }\end{array}$ \\
\hline $\begin{array}{l}\text { HPGe + Doubles } \\
\text { Neutron + Neutron } \\
\text { Energy }\end{array}$ & HPGe & $\begin{array}{l}\text { Yes. }(\alpha, n) \text { via } \\
\text { HPGe + neutron } \\
\text { energy. }\end{array}$ & HPGe & HPGe & $\begin{array}{l}\mathrm{HPGe}+(\alpha, n)+ \\
\text { neutron energy }\end{array}$ & $\begin{array}{l}\text { HPGe or } \\
\text { neutron }\end{array}$ \\
\hline $\begin{array}{l}\text { HPGe + Multiplicity } \\
\text { (NMC) }\end{array}$ & HPGe & Yes & HPGe & HPGe & HPGe plus $(\alpha, n)$ & $\begin{array}{l}\text { HPGe or } \\
\text { neutron }\end{array}$ \\
\hline
\end{tabular}


Table 4.1 is ordered roughly in increasing complexity and cost. The first two entries do not provide a measure of all six attributes, but all the other systems do. The remaining entries are also giving in order of increasing confidence in the determination of the mass attribute, but this is approached asymptotically, not linearly. Thus, while the NMC has the highest confidence level, there are several alternative systems that can provide a full attribute measurement with a high level of confidence and a significant reduction in cost and complexity.

\subsection{Discussion of Technologies}

HPGe detectors (one or more) alone, with MME or more advanced analysis, can provide a measure of all the desired attributes. Because of uncertainties in gamma ray attenuation and conservative modeling assumptions, the plutonium mass measurement has been described as a minimum mass estimate, whereas neutron coincidence does not share the attenuation limitation and can provide a more accurate measure of mass based upon an empirical calibration. With more complete analysis or an empirical calibration, it is likely that HPGe systems can also provide an accurate mass measurement without neutron data. Neutron measurements measure the combination of fission and singles neutrons, which are additionally complicated by multiplication in the source material, e.g. a $4 \mathrm{~kg}$ plutonium mass can have multiplication double the number of neutrons and increase the number of pairs by an order of magnitude. Multiplication is also effected by shape of the sample. However, it is possible to use standards of varying mass to calibrate a system, and thus eliminate multiplication as an independent measured parameter.

Combined systems add complexity and cost, but have the advantage of increased confidence in a measured attribute, if the information from the various detector systems is combined. For example, a measurement of the neutron energy spectrum would add information about the metal versus compound (“oxide”) attribute. Below, we discuss further the four combined systems shown in Table 4.1.

\subsection{HPGe Plus Singles Neutron Measurement with Energy Determination}

Adding a singles neutron detector to a HPGe detector increases the confidence in the plutonium mass. A set of Bonner spheres could be used to measure the neutron flux and a rough neutron energy spectrum. Bonner spheres have a lithium-iodide scintillator or helium-3 counter placed in the center of polyethylene moderating spheres up to 12-inches in diameter. For such a combination

- the gross neutron count would be proportional to the plutonium mass assuming the dominant neutron source is ${ }^{240} \mathrm{Pu}$ spontaneous fission

- problems with spoofs using $(\alpha, n)$ interactions could be discovered via the neutron energy spectrum

- problems with neutron multiplication could be eliminated if the Bonner sphere signals are processed to prevent more than one count per fission event time period $(0.1 \mathrm{~ms})$ 
- neutron energy spectrometry could also identify plutonium oxide or other compounds

- there are other neutron energy spectrometry alternatives to Bonner spheres, including

- time of flight

- layers of fiber optics

- selected activation foils (counting induced gamma rays after exposure or prompt gamma rays during exposure)

- ring ratio detectors

- neutron threshold reaction detector.

\subsection{HPGe Plus Doubles Neutron Measurement}

Adding a doubles coincidence neutron detector to a HPGe detector provides one additional parameter of neutron information, which can be used to more effectively measure the $(\alpha, n)$ component of the neutron spectrum. As implemented with the HLNCC-2, either an alpha value or a multiplication factor is assumed. With the added information of neutron energy, the $(\alpha, n)$ contribution can be eliminated or modeled, and a precise plutonium mass value and multiplication factor obtained. It has also been noted that the multiplication effect can be effectively reduced or eliminated via electronics. With comparable neutron detection efficiency, the duration of the "doubles" measurement is significantly less than the multiplicity counter because one does not have to wait for a statistically significant count to accumulate for the much less efficient higher levels of coincidence.

\subsection{HPGe Plus Multiplicity Neutron Measurement}

Multiplicity neutron detector systems measure an additional neutron parameter by measuring neutron multiplication. Combined with a HPGe detector, a multiplicity detector provides a full determination of the neutron parameters. When combined with the MME analysis, and the neutron energy measurement, the attributes can be over-determined, which provides increased confidence in the total measurement. The disadvantage of the multiplicity-based system is its lack of flexibility in operation and significant increase in cost. In addition, it has been noted that the Russians lack experience in multiplicity counting. This could imply that they would be reluctant to commit to such a system requirement.

\subsection{HPGe Plus Fast Neutron/Gamma Measurement}

Fast neutron coincidence detector systems based upon plastic scintillator (which are also sensitive to the more prolific gamma rays) provide a measure of the neutron energy spectrum via time-of-flight and a measure of the plutonium mass via the spontaneous fission rate. Combined with a HPGe detector, this configuration has the advantages of a doubles neutron detector plus a neutron energy measurement. The 
combined gamma ray coincidence with neutron time of flight, made possible with this configuration, can give a determination of the fission rate and the crude neutron energy spectrum. The fission rate accurately provides the plutonium mass and the neutron energy spectrum provides the $(\alpha, n)$ contribution, and information about the "oxide" attribute.

\subsection{Optimal System Configurations}

Several of the systems listed in Table 4.1 can provide the optimal combination of attribute measurement, confidence and cost effectiveness. These are shown in Table 6.1 in increasing order of complexity, with their pros and cons for utilization as an attribute determination system. Each of these systems can be improved with regard to quality of measurement result from their current state of implementation (e.g. MME may be a useful analysis technique to use with an HPGe system).

Table 6.1. Optimal System Configurations

\begin{tabular}{|c|c|c|c|c|}
\hline & Pros & Cons & $\begin{array}{c}\text { Estimated } \\
\text { Measurement Time }\end{array}$ & Estimated Cost \\
\hline $\begin{array}{l}\text { HPGe Only } \\
\text { (MME) }\end{array}$ & $\begin{array}{ll}\text { - } & \text { Simplest and least } \\
\text { expensive system } \\
\text { - } & \text { Least expensive } \\
\end{array}$ & $\begin{array}{ll}- & \text { Presently } \\
\text { underestimates mass by } \\
\text { up to a factor of } 2 \\
\end{array}$ & - 10 minutes & $\begin{array}{l}\text { Baseline of } \\
\text { about } \$ 50 \mathrm{~K}\end{array}$ \\
\hline $\begin{array}{l}\text { HPGe + Fast } \\
\text { N-Gamma TOF }\end{array}$ & $\begin{array}{l}\text { - Does not need high } \\
\text { efficiency neutron } \\
\text { detectors }\end{array}$ & 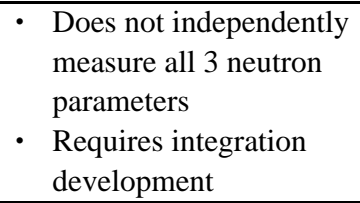 & - 60 minutes & 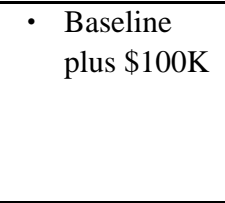 \\
\hline $\begin{array}{l}\text { HPGe + Singles } \\
\text { Neutron + Neutron } \\
\text { Energy }\end{array}$ & 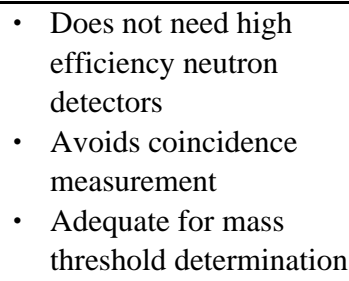 & $\begin{array}{l}\text { - Does not independently } \\
\text { measure all } 3 \text { neutron } \\
\text { parameters } \\
\text { - } \text { Requires integration } \\
\text { development }\end{array}$ & - 20 minutes & $\begin{array}{ll}\text { - } & \text { Baseline } \\
& \text { plus } \$ 100 \mathrm{~K}\end{array}$ \\
\hline $\begin{array}{l}\text { HPGe + Doubles } \\
\text { Neutron }\end{array}$ & $\begin{array}{l}\text { - } \begin{array}{l}\text { Does not need high } \\
\text { efficiency neutron }\end{array} \\
\text { detectors } \\
\text { - Adequate for mass } \\
\text { threshold determination }\end{array}$ & $\begin{array}{l}\text { - Does not independently } \\
\text { measure all } 3 \text { neutron } \\
\text { parameters }\end{array}$ & - 20-60 minutes & $\begin{array}{ll}\text { - } & \text { Baseline } \\
& \text { plus } \$ 200 \mathrm{~K}\end{array}$ \\
\hline $\begin{array}{l}\text { HPGe + } \\
\text { Multiplicity } \\
\text { (NMC) } \\
\end{array}$ & $\begin{array}{ll}\text { - } & \text { Directly measures all } \\
& 3 \text { neutron parameters } \\
\text { - } & \text { Most complex } \\
\end{array}$ & $\begin{array}{ll}- & \text { Needs high efficiency } \\
& \text { neutron detectors } \\
\text { - } & \text { Expensive } \\
\end{array}$ & - 60 minutes & $\begin{array}{ll}\text { - } & \text { Baseline } \\
& \text { plus } \$ 1000 \mathrm{~K}\end{array}$ \\
\hline
\end{tabular}


The estimate time for a measurement is shown, and varies from 10 minutes to one hour. The estimated cost is the hardware system cost for implementation. All require a HPGe system at a cost of about $\$ 50 \mathrm{~K}$. The additional hardware for neutron measurements varies from about $\$ 100 \mathrm{~K}$ to $\$ 1 \mathrm{M}$. For example, a Passport system from Canberra with a HPGe and a neutron singles measurement costs about $\$ 100 \mathrm{~K}$, while a Canberra multiplicity system costs about $\$ 800 \mathrm{~K}$. Each system can be implemented from commercial hardware in some form. There are laboratory developed research instruments that can also be utilized for improved measurements in most of these configurations. For any system, integration, including an information barrier, would add an additional man-year cost of about \$300K.

\subsection{Conclusion}

Our conclusion is that there is a rank ordered set of options for attribute determination. A system containing only a large, high-resolution HPGe detector could provide a complete measurement of the six attributes. The MME method of analysis can be utilized with any HPGe measurement system to obtain maximal information from the HPGe data. Adding neutron detectors to the system increases the number of parameters measured, particularly with regard to the plutonium mass, and thus increases the confidence in the overall result. A system with a HPGe measurement of the gamma ray spectrum plus a measure of neutron doubles, or a system with a HPGe measurement and a rough measurement of neutron energy along with neutron singles, has the highest cost-benefit effectiveness of combined systems.

\subsection{References}

Beddingfield, D. H. and F. E. Cecil. 1998. Identification of Fissile Materials from Fission Product Gamma-Ray Spectra. Nuclear Instruments and Methods in Physics Research, Section A, 417:405-412.

Breeding, E., et al. 1997. In Proceedings of the Institute of Nuclear Materials Management, $38^{\text {th }}$ Annual Meeting, July 20-24, 1997 in Phoenix, Arizona, Vol. XXVI. "New Processor for Fissile System Measurements for NMC\&A.”

Knoll, G. 2000. Radiation Detection and Measurement. John Wiley and Sons, New York.

Romero, R. 1998. Application Guide to Neutron Multiplicty Counting. Los Alamos National Laboratory.

Reilly, D., N. Ensslin, H. Smith, Jr., and S. Kreiner, eds. 1991. Passive Nondestructive Assay of Nuclear Materials. ISBN 0-16-032724-5. U.S. Government Printing Office, Washington, D.C. 